\title{
Characteristics of Frost in a Major Wheat-growing Region of Australia
}

\author{
Rizaldi Boer, ${ }^{\mathrm{A}}$ Lindsay C. Campbell ${ }^{\mathrm{A}}$ and David J. Fletcher ${ }^{\mathrm{B}}$ \\ A Department of Crop Sciences, University of Sydney, N.S.W. 2006. \\ B Department of Mathematics and Statistics, University of Otago, \\ Dunedin, New Zealand.
}

\begin{abstract}
Frost at anthesis of wheat reduces grain set. Characteristics of frost in a large section of the wheat belt of one Australian state (N.S.W.) are described. Using cluster analysis, the region can be divided into four homogeneous areas according to five general characteristics of frost. These characteristics are the mean Julian day of first and last frost, the mean number of frost days, the proportion of single-day frosts (days on which a frost did not occur on the following day) from August to October and the proportion of frost free periods from August to October of less than 5 days' duration.

All these characteristics were found to be closely related to altitude in all areas, but not to latitude or longitude. Within each area, regression equations were developed which explained at least $87 \%$ of the variation in four of the general characteristics. Thus, altitude appears to be a useful predictor for these characteristics.

The validity of each equation was tested using three independent data sets. The mean percentage errors for the mean Julian day of first and last frost and the proportion of single-day frosts from August to October were 5, 5 and $8 \%$ respectively. Errors for the mean number of frost days and proportion of frost free periods from August to October of less than 5 days duration were approximately $7 \%$ for one site and approximately $20 \%$ for two other sites.

The characteristics of frost in the period in which most winter crops flower are also described. The characteristics are the mean date of last heavy frost and last frost, and frost spells in each of August, September and October. In order to minimize risk from frost during anthesis and from high temperature and water stress during grain filling, this analysis suggests that anthesis should occur in early/mid September, late September/early October and early/mid October for the western, central and eastern parts of the region respectively. For areas in the north-eastern and south-eastern parts that are above $500 \mathrm{~m}$, anthesis should occur mid/late October and early/mid November respectively. These analytical findings are consistent with field studies on wheat.

A weak negative correlation between the first and the last frost is present in most of the sites of the region. This suggests that if in any particular year the first frost occurs earlier than its long-term mean, then the last frost tends to occur later than its long-term mean.
\end{abstract}

Keywords: anthesis, cluster analysis, frost, weighted regression, wheat.

\section{Introduction}

Frost damage is often reported to be a factor causing serious losses in wheat crops, e.g. in Kansas, U.S.A. (Paulsen and Heyne 1983); in Japan (Uemura et al. 1972); in Quetta, Pakistan (Rees et al. 1990); in Chaco and Formosa, Argentina (Cettour and Nissi 1985); in Glen, South Africa (Singels 1992); in Australia 
(McCann and Rooney 1955; Chambers 1962; Loss 1988; Woodruff 1988); and in N.S.W. in particular (Fitzsimmons 1961, 1966; Brown and Fitzsimmons 1964; Marcellos and Doyle 1974; Single 1986; Cooper 1992). In N.S.W., the losses vary between 5 and 35\%, with heavy frosts in late September and early October being responsible for most of the damage (Brown and Fitzsimmons 1964; Fitzsimmons 1960, 1966; Fitzsimmons and Aitkin 1970; Single 1986). The greatest losses occurred in the 1965 season when heavy frosts in early October caused a yield loss of $50 \%$ (Fitzsimmons 1966).

Incorporating genetic resistance to freezing stress into new varieties is one potential way to avoid frost injury (Fletcher and Cullis 1988; Fletcher 1990). However, this approach may be difficult to implement as the genetics of resistance are complex and many varieties are already near the upper limit of tolerance to this stress (Richards 1991). Another strategy is to optimize the sowing time so that anthesis occurs after the last heavy frost. Marcellos and Doyle (1974) proposed that heading should be between 1 and 3 weeks after the mean last date of frost, whereas Syme (1973) and Fischer (1979) suggested that anthesis should occur after the mean date of the last frost plus one standard deviation. The objectives of this paper are (i) to examine the incidence of frost as a function of geographical variables, (ii) to provide statistical tools for the examination of frost incidence patterns, and (iii) to validate the analysis using the results of three field studies on wheat.

Table 1. Altitude and location of meteorological stations used in this study

\begin{tabular}{rlcccc}
\hline No. & Station & $\begin{array}{c}\text { Altitude } \\
(\mathrm{m})\end{array}$ & $\begin{array}{c}\text { Latitude } \\
\left({ }^{\circ} \mathrm{S} .\right)\end{array}$ & $\begin{array}{c}\text { Longitude } \\
\left({ }^{\circ} \mathrm{E} .\right)\end{array}$ & $\begin{array}{c}\text { Period of } \\
\text { record }\end{array}$ \\
\hline 1 & Goondiwindi & $216 \cdot 0$ & $28 \cdot 53$ & $150 \cdot 30$ & $1957-1991$ \\
2 & Peak Hill & $267 \cdot 0$ & $32 \cdot 72$ & $148 \cdot 18$ & $1966-1992$ \\
3 & Tullamore & $239 \cdot 0$ & $32 \cdot 63$ & $147 \cdot 57$ & $1971-1986$ \\
4 & Condobolin & $195 \cdot 0$ & $33 \cdot 08$ & $147 \cdot 25$ & $1965-1989$ \\
5 & Coonamble & $180 \cdot 0$ & $30 \cdot 97$ & $148 \cdot 38$ & $1967-1989$ \\
6 & Nyngan & $177 \cdot 0$ & $31 \cdot 56$ & $147 \cdot 20$ & $1959-1989$ \\
7 & Warren & $198 \cdot 0$ & $31 \cdot 78$ & $147 \cdot 77$ & $1969-1982$ \\
8 & Mungindi & $160 \cdot 0$ & $28 \cdot 99$ & $148 \cdot 99$ & $1967-1992$ \\
9 & Walgett & $131 \cdot 0$ & $30 \cdot 02$ & $148 \cdot 12$ & $1957-1989$ \\
10 & Baradine & $302 \cdot 0$ & $30 \cdot 95$ & $149 \cdot 67$ & $1967-1985$ \\
11 & Narrabri & $212 \cdot 0$ & $30 \cdot 33$ & $149 \cdot 75$ & $1962-1989$ \\
12 & Moree & $212 \cdot 1$ & $29 \cdot 47$ & $149 \cdot 85$ & $1965-1989$ \\
13 & Barraba & $500 \cdot 0$ & $30 \cdot 38$ & $150 \cdot 62$ & $1966-1985$ \\
14 & Gunnedah & $307 \cdot 0$ & $31 \cdot 03$ & $150 \cdot 26$ & $1965-1985$ \\
15 & Quirindi & $390 \cdot 0$ & $31 \cdot 52$ & $150 \cdot 68$ & $1967-1985$ \\
16 & Tamworth & $404 \cdot 0$ & $31 \cdot 08$ & $150 \cdot 85$ & $1957-1989$ \\
17 & Coonabarabran & $509 \cdot 0$ & $31 \cdot 28$ & $149 \cdot 28$ & $1957-1988$ \\
18 & Dunedoo & $388 \cdot 0$ & $32 \cdot 02$ & $149 \cdot 40$ & $1965-1991$ \\
19 & Canowindra & $300 \cdot 0$ & $33 \cdot 57$ & $148 \cdot 67$ & $1965-1981$ \\
20 & Dubbo & $275 \cdot 0$ & $32 \cdot 22$ & $148 \cdot 57$ & $1957-1989$ \\
21 & Forbes & $237 \cdot 0$ & $33 \cdot 38$ & $148 \cdot 02$ & $1957-1985$ \\
22 & Molong & $529 \cdot 0$ & $33 \cdot 10$ & $148 \cdot 87$ & $1957-1975$ \\
23 & Parkes & $339 \cdot 0$ & $33 \cdot 13$ & $148 \cdot 18$ & $1957-1988$ \\
24 & Wellington & $390 \cdot 0$ & $32 \cdot 57$ & $148 \cdot 98$ & $1965-1985$ \\
\hline & & & & &
\end{tabular}




\section{Methods}

\section{Study Region}

The region studied was the north and central wheat belt of New South Wales $(2 \cdot 3$ million ha; Fig. 1) where frosts are a major problem. Data indicating frost occurrence at 24 sites were obtained from the Australian Bureau of Meteorology. The elevation and location of the sites are presented in Table 1 and Fig. 1.

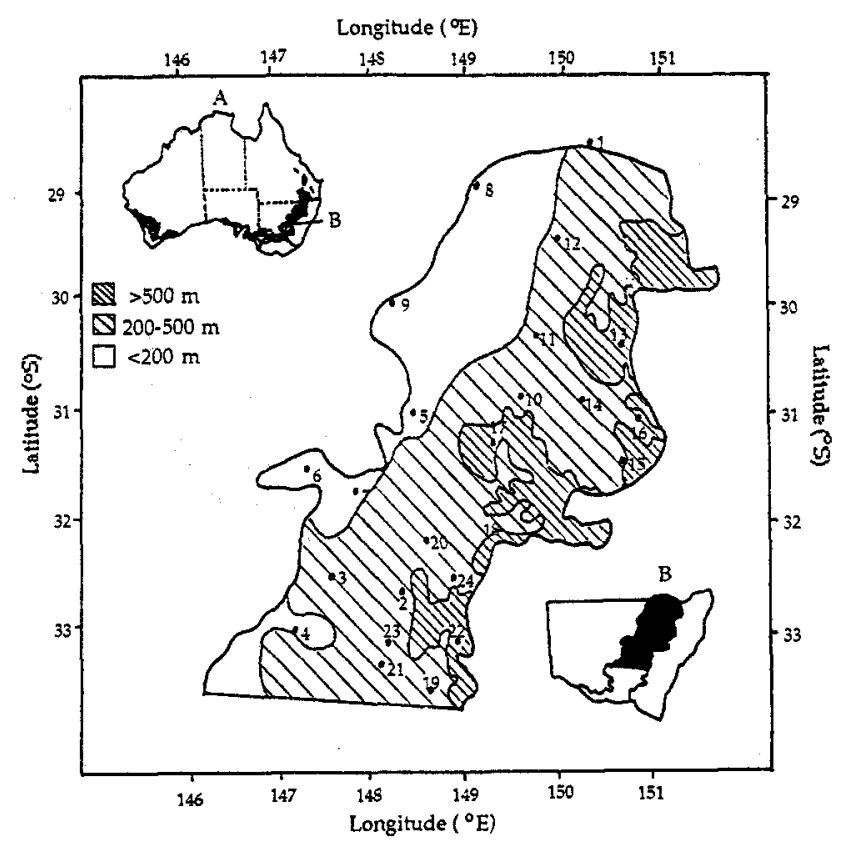

Fig. 1. The topography and geographical location of the meteorological stations. Inset $A$ shows the Australian wheat belt. Inset $B$ delineates the study area in relation to the N.S.W. wheat growing region. Numbers on the map indicate the location of the stations.

\section{Method of Analysis}

\section{General characteristics of frost}

The region was divided into homogeneous areas using cluster analysis based on the furthest neighbour algorithm (Chatfield and Collins 1980), the analysis covering the following frost characteristics:

(1) mean Julian day of first frost (FFD),

(2) mean Julian day of last frost (LFD),

(3) mean number of frost days per year (NFD),

(4) proportion of single-day frosts from August to October (PFS1), and

(5) proportion of frost-free periods from August to October that are of less than 5 days duration (PNFS4).

The coefficients of variation of these characteristics are presented in Table 2.

In developing regression equations for these frost characteristics, altitude, latitude and longitude were used as predictors. To allow for the precision of the characteristics varying across sites, a weighted form of regression analysis was employed to develop the equations. A simple graphical technique was used to decide whether the same regression coefficients could be used in different areas (Fletcher and Boer 1992; Boer et al. 1993). The quality of fit of 
the equations was assessed using $R_{\mathrm{wls}}^{2}$ (Willet and Singer 1988) and the square root of the mean of the squared residuals (RMS) for each area. $R^{2}$ wls is defined as:

$$
R_{\mathrm{wls}}^{2}=1-\left[R S S /\left([n-1] s_{\mathrm{y}}^{2}\right)\right],
$$

where RSS is the sum of squares of the residuals, $s_{\mathrm{y}}{ }^{2}$ is the variance of the dependent variable and $n$ is the number of observations.

The validity of the equations was tested against data which were not used in developing equations. The data used were from additional meteorological stations near Condobolin, Gunnedah and Wellington. The geographical positions of the corresponding stations are $33.08^{\circ} \mathrm{S}$., $147 \cdot 57^{\circ} \mathrm{E} . ; 30 \cdot 98^{\circ} \mathrm{S}$., $150 \cdot 25^{\circ} \mathrm{E}$.; and $32.57^{\circ} \mathrm{S}$., $148 \cdot 95^{\circ} \mathrm{E}$.; with altitudes of 199 , 306 , and $304 \mathrm{~m}$. The length of record of the respective stations was 20,22 and 25 years.

The relationship between the date of the first and last frost at a particular site was also investigated using regression techniques.

\section{Specific characteristics of frost}

The study region was divided into areas based on the characteristics of frost during the periods in which wheat may come into head. The areas were delineated firstly using cluster analysis on the mean dates of last heavy frost (LHFD) and last frost (LFD), where a heavy frost is defined as one for which the screen minimum temperature is less than $0^{\circ} \mathrm{C}$ (cf. Linacre and Hobbs 1977); and secondly, on the number of consecutive frost days (the length of a frost spell) in each of August, September and October. The characteristics for each month were:

(1) maximum length of a frost spell (MLS),

(2) probability of a frost spell of at least 2 days' duration (PLS2),

(3) maximum number of frost spells (MNS), and

(4) probability of having one frost spell (PH1S), at least two (PH2S), three (PH3S), four (PH4S), five (PH5S) or six frost spells (PH6S).

Table 2. Coefficients of variation for the five general characteristics of frost

\begin{tabular}{rlrrrrr}
\hline No. & Station & $\begin{array}{r}\text { FFD } \\
(\%)\end{array}$ & $\begin{array}{c}\text { LFD } \\
(\%)\end{array}$ & $\begin{array}{c}\text { NFD } \\
(\%)\end{array}$ & $\begin{array}{r}\text { PFS1 } \\
(\%)\end{array}$ & $\begin{array}{r}\text { PNFS4 } \\
(\%)\end{array}$ \\
\hline 1 & Goondiwindi & $9 \cdot 9$ & $6 \cdot 8$ & $50 \cdot 6$ & $7 \cdot 6$ & $10 \cdot 4$ \\
2 & Peak Hill & $12 \cdot 6$ & $6 \cdot 2$ & $37 \cdot 6$ & $7 \cdot 6$ & $12 \cdot 0$ \\
3 & Tullamore & $11 \cdot 9$ & $6 \cdot 0$ & $25 \cdot 4$ & $9 \cdot 7$ & $7 \cdot 2$ \\
4 & Condobolin & $14 \cdot 1$ & $7 \cdot 8$ & $42 \cdot 7$ & $7 \cdot 3$ & $6 \cdot 5$ \\
5 & Coonamble & $8 \cdot 7$ & $6 \cdot 8$ & $43 \cdot 2$ & $8 \cdot 8$ & $9 \cdot 4$ \\
6 & Nyngan & $10 \cdot 2$ & $5 \cdot 9$ & $36 \cdot 8$ & $8 \cdot 0$ & $11 \cdot 0$ \\
7 & Warren & $10 \cdot 6$ & $3 \cdot 9$ & $37 \cdot 5$ & $9 \cdot 8$ & $8 \cdot 6$ \\
8 & Mungindi & $11 \cdot 7$ & $8 \cdot 2$ & $53 \cdot 8$ & $10 \cdot 3$ & $19 \cdot 4$ \\
9 & Walgett & $8 \cdot 9$ & $7 \cdot 3$ & $49 \cdot 2$ & $8 \cdot 8$ & $11 \cdot 5$ \\
10 & Baradine & $9 \cdot 8$ & $7 \cdot 2$ & $36 \cdot 3$ & $8 \cdot 8$ & $7 \cdot 5$ \\
11 & Narrabri & $13 \cdot 3$ & $6 \cdot 0$ & $36 \cdot 9$ & $8 \cdot 0$ & $7 \cdot 3$ \\
12 & Moree & $12 \cdot 7$ & $12 \cdot 4$ & $36 \cdot 1$ & $8 \cdot 5$ & $6 \cdot 6$ \\
13 & Barraba & $16 \cdot 2$ & $6 \cdot 8$ & $20 \cdot 6$ & $8 \cdot 6$ & $4 \cdot 2$ \\
14 & Gunnedah & $13 \cdot 1$ & $10 \cdot 3$ & $31 \cdot 5$ & $8 \cdot 1$ & $10 \cdot 3$ \\
15 & Quirindi & $10 \cdot 7$ & $5 \cdot 1$ & $22 \cdot 0$ & $9 \cdot 9$ & $5 \cdot 3$ \\
16 & Tamworth & $12 \cdot 5$ & $7 \cdot 5$ & $33 \cdot 1$ & $6 \cdot 4$ & $7 \cdot 1$ \\
17 & Coonabarabran & $10 \cdot 6$ & $6 \cdot 2$ & $25 \cdot 6$ & $7 \cdot 3$ & $2 \cdot 8$ \\
18 & Dunedoo & $17 \cdot 2$ & $8 \cdot 6$ & $38 \cdot 0$ & $6 \cdot 9$ & $5 \cdot 0$ \\
19 & Canowindra & $13 \cdot 1$ & $11 \cdot 9$ & $42 \cdot 1$ & $9 \cdot 3$ & $6 \cdot 4$ \\
20 & Dubbo & $11 \cdot 5$ & $6 \cdot 3$ & $28 \cdot 4$ & $5 \cdot 9$ & $5 \cdot 6$ \\
21 & Forbes & $11 \cdot 8$ & $6 \cdot 5$ & $29 \cdot 6$ & $7 \cdot 5$ & $5 \cdot 0$ \\
22 & Molong & $17 \cdot 5$ & $13 \cdot 6$ & $32 \cdot 4$ & $10 \cdot 1$ & $2 \cdot 6$ \\
23 & Parkes & $11 \cdot 5$ & $7 \cdot 8$ & $32 \cdot 9$ & $6 \cdot 8$ & $11 \cdot 8$ \\
24 & Wellington & $19 \cdot 6$ & $6 \cdot 4$ & $29 \cdot 9$ & $7 \cdot 7$ & $5 \cdot 5$ \\
Mean & & $12 \cdot 5$ & $7 \cdot 6$ & $35 \cdot 5$ & $8 \cdot 2$ & $7 \cdot 9$ \\
\hline
\end{tabular}




\section{Results}

\section{General Characteristics}

Based on the general characteristics of frost, the region could be divided into two homogeneous areas, with each of these being further divided into two subareas (Fig. 2). This division appears to be closely related to elevation with most of Area 2 being at elevations greater than $250 \mathrm{~m}$ (Fig. 2; cf. Fig. 1). The Julian day of first frost decreases from west to east while Julian day of last frost increases, thereby increasing the length of frost period (Table 3 ). The increase

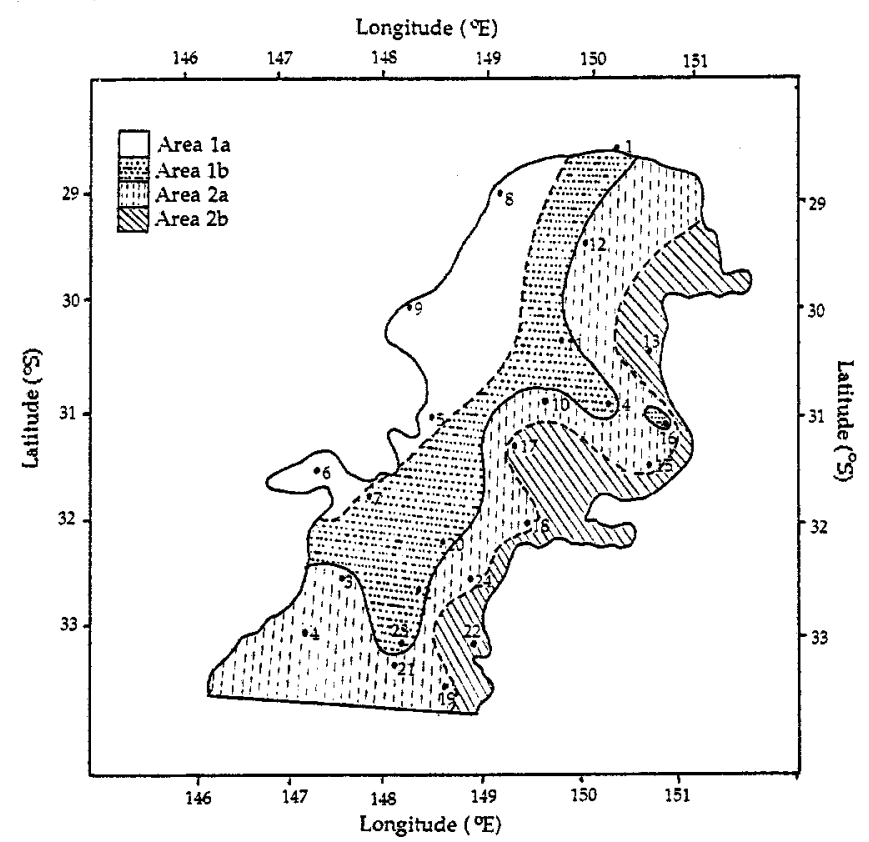

Fig. 2. The division of the region based on the general characteristics of frost. The boundary lines shown are based on the cluster analysis and the elevation contours.

Table 3. Mean Julian day of first (FFD) and last (LFD) frost, mean number of frost days (NFD), proportion of single-day frosts, and proportion of frost-free periods that are of less than 5 days' duration (PNFS4) from August to October

Numbers in parentheses are pooled standard errors

\begin{tabular}{lccccc}
\hline No. & Frost & \multicolumn{2}{c}{ Area 1 } & \multicolumn{3}{c}{ Area 2 } \\
& characteristics & $\mathrm{a}$ & $\mathrm{b}$ & $\mathrm{a}$ & $\mathrm{b}$ \\
\hline 1 & FFD & 157 & 145 & 131 & 115 \\
& & $(16)$ & $(17)$ & $(18)$ & $(16)$ \\
2 & LFD & 240 & 257 & 271 & 284 \\
& & $(17)$ & $(18)$ & $(23)$ & $(25)$ \\
3 & NFD & 20 & 30 & 49 & 82 \\
& & $(9)$ & $(11)$ & $(16)$ & $(22)$ \\
4 & PFS1 & $60 \cdot 5$ & $57 \cdot 1$ & $46 \cdot 2$ & $35 \cdot 4$ \\
& & $(5 \cdot 5)$ & $(4 \cdot 3)$ & $(3 \cdot 9)$ & $(3 \cdot 1)$ \\
5 & PNFS4 & $50 \cdot 2$ & $51 \cdot 7$ & $64 \cdot 1$ & $80 \cdot 0$ \\
& & $(5 \cdot 9)$ & $(4 \cdot 6)$ & $(3 \cdot 9)$ & $(2 \cdot 6)$ \\
\hline
\end{tabular}


in the length of frost period is associated with an increase in the number of frost days (Table 3). From August to October, the probability of having up to 4 consecutive frost free days is less than $52 \%$ in Area 1, while in Area 2 it is greater than $64 \%$ (Table 3). The length of a frost spell is mostly more than 1 day in Area 2 (Table 3).

(a)

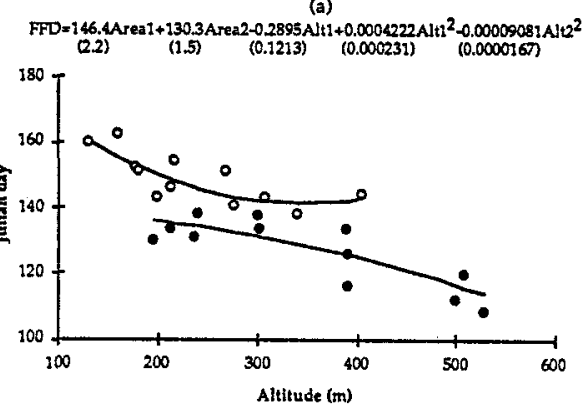

(b)

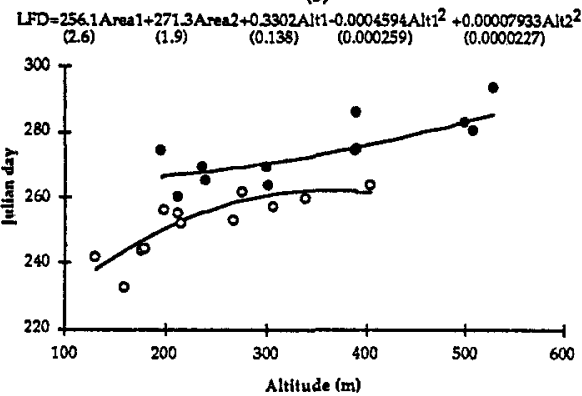

(c)

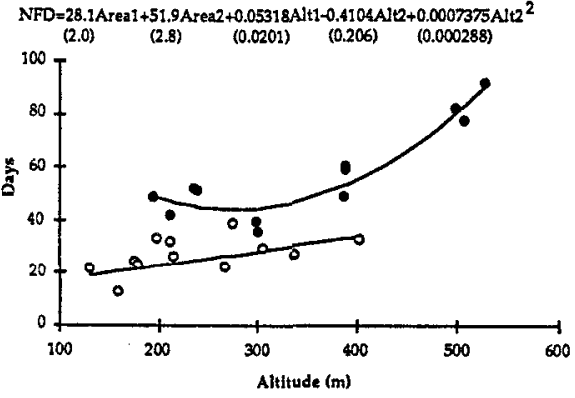

(d) PFS1 $=57.9$ Area1 +45.3 Area2 +0.1416 A $12-0.0002474 \mathrm{Alt}^{2}$

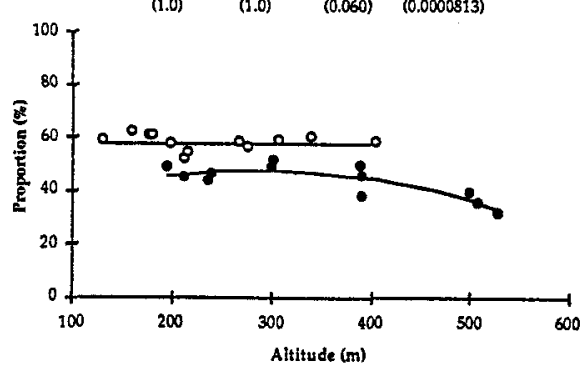

(e)

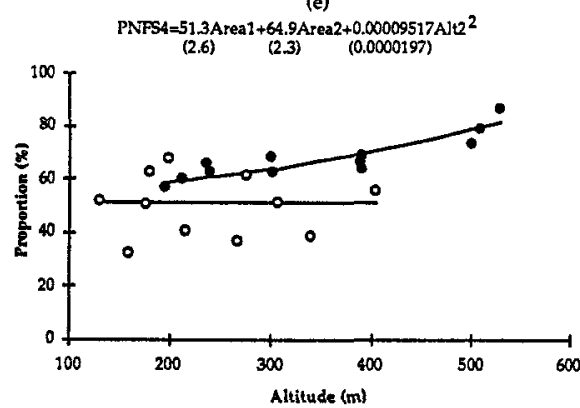

Fig. 3. The relationship between altitude and (a) mean Julian day of first frost (FFD), (b) mean Julian day of last frost (LFD), (c) mean number of frost days (NFD), (d) proportion (heavy frost days)/(frost days) (PHFD), (e) proportion of frosts from August to October that are of 1 day duration (PFS1), and $(f)$ proportion of frost-free periods from August to October that are of less than 5 days' duration (PNFS4). The numbers in parentheses are standard errors. The predictor altitude was centred before analysis; thus, alt is altitude minus $300 \mathrm{~m}$, and alt $^{2}$ is altitude ${ }^{2}$ minus 100000 . o = Area $1 ; \bullet=$ Area 2. 
Inspection of the correlation coefficients between the geographical variables and the characteristics indicated that altitude was the predominant variable. Furthermore, when regression equations were fitted for the whole region, neither latitude nor longitude approached significance after accounting for altitude. Therefore, only altitude was used as a predictor in developing the equations.

The regression analysis suggested that the effect of altitude on the frost characteristics was significantly different between the two areas (Fig. 3). The RMS for the NFD and PNFS4 equations were smaller in Area 2, implying that these fit better if they are applied when the altitude is more than $250 \mathrm{~m}$ (Table 4). In contrast, the FFD, LFD and PFS1 equations fitted better at lower altitude. The effects of altitude on PFS1 and PNFS4 were not significant in Area 1.

A weak negative linear relationship between the timing of first and last frost was found at most sites; the relationship was strongest at Coonamble, Warren and Dubbo.

Table 4. Goodness of fit of the regression equations

\begin{tabular}{lccrc}
\hline No. & $\begin{array}{c}\text { Frost } \\
\text { characteristics }\end{array}$ & $\begin{array}{c}R^{2} \text { wls } \\
(\%)\end{array}$ & Area 1 & RMS \\
\hline 1 & FFD & 88 & $4 \cdot 3$ & Area 2 \\
2 & LFD & 87 & $4 \cdot 7$ & $5 \cdot 2$ \\
3 & NFD & 91 & $6 \cdot 0$ & $5 \cdot 5$ \\
4 & PFS1 & 88 & $2 \cdot 7$ & $5 \cdot 5$ \\
5 & PNFS4 & $78^{\mathrm{A}}$ & $11 \cdot 0$ & $3 \cdot 2$ \\
\hline
\end{tabular}

A Area 2 only. Unit of measurement of RMS for FFD and LFD is day and the remainder is percent.

The equations were validated at three meteorological stations which had not been used in the construction of the equations. The prediction errors in the validation study ranged from 0.7 to $22.5 \%$, with a mean of $9.8 \%$. In general, the prediction errors for FFD, LFD and PFS1 were less than $7 \%$, while for NFD and PNFS4 were greater than $15 \%$ at two of the three sites (Table 5).

Table 5. Comparison between long-term mean (LTM) and estimated (EST) frost characteristics of Condobolin, Gunnedah and Wellington

\begin{tabular}{llrrrrrrrrr}
\hline No. & Frost & \multicolumn{3}{c}{ Condobolin } & \multicolumn{3}{c}{ Gunnedah } & \multicolumn{3}{c}{ Wellington } \\
& characteristics & LTM & EST & $\begin{array}{c}\% \\
\text { Error }\end{array}$ & LTM & EST & $\%$ & LTM & EST & $\%$ \\
Error \\
\hline 1 & FFD & 140 & 136 & $2 \cdot 9$ & 156 & 142 & $9 \cdot 0$ & 135 & 131 & $3 \cdot 0$ \\
2 & LFD & 269 & 267 & $0 \cdot 7$ & 247 & 260 & $5 \cdot 3$ & 262 & 279 & $6 \cdot 5$ \\
3 & NFD & 40 & 49 & $22 \cdot 5$ & 23 & 28 & $21 \cdot 7$ & 42 & 45 & $7 \cdot 1$ \\
4 & PFS1 & 45 & 46 & $2 \cdot 2$ & 50 & 58 & $16 \cdot 0$ & 45 & 48 & $6 \cdot 7$ \\
5 & PNFS4 & 50 & 59 & $18 \cdot 0$ & 43 & 51 & $18 \cdot 6$ & 60 & 64 & $6 \cdot 7$ \\
\hline
\end{tabular}

\section{Specific Characteristics}

\section{Mean Julian day of Last Heavy Frost (LHFD) and Last Frost (LFD)}

The division of the region using LHFD and LFD was consistent with that using the five general characteristics. However, for these specific characteristics, 
we used a higher level of clustering to examine their spatial variation in detail. We found that 12 clusters (areas) were most effective (Fig. 4). Within each area, analysis of variance showed no significant difference between the site means for both LHFD and LFD. We therefore used the overall mean and the pooled standard deviation as area summaries. The mean varied from 30 July to 8 October and from 19 August to 25 October for LHFD and LFD respectively, while the pooled standard deviation varied from 12 to 28 days and from 13 to 31 days respectively (Fig. 4).

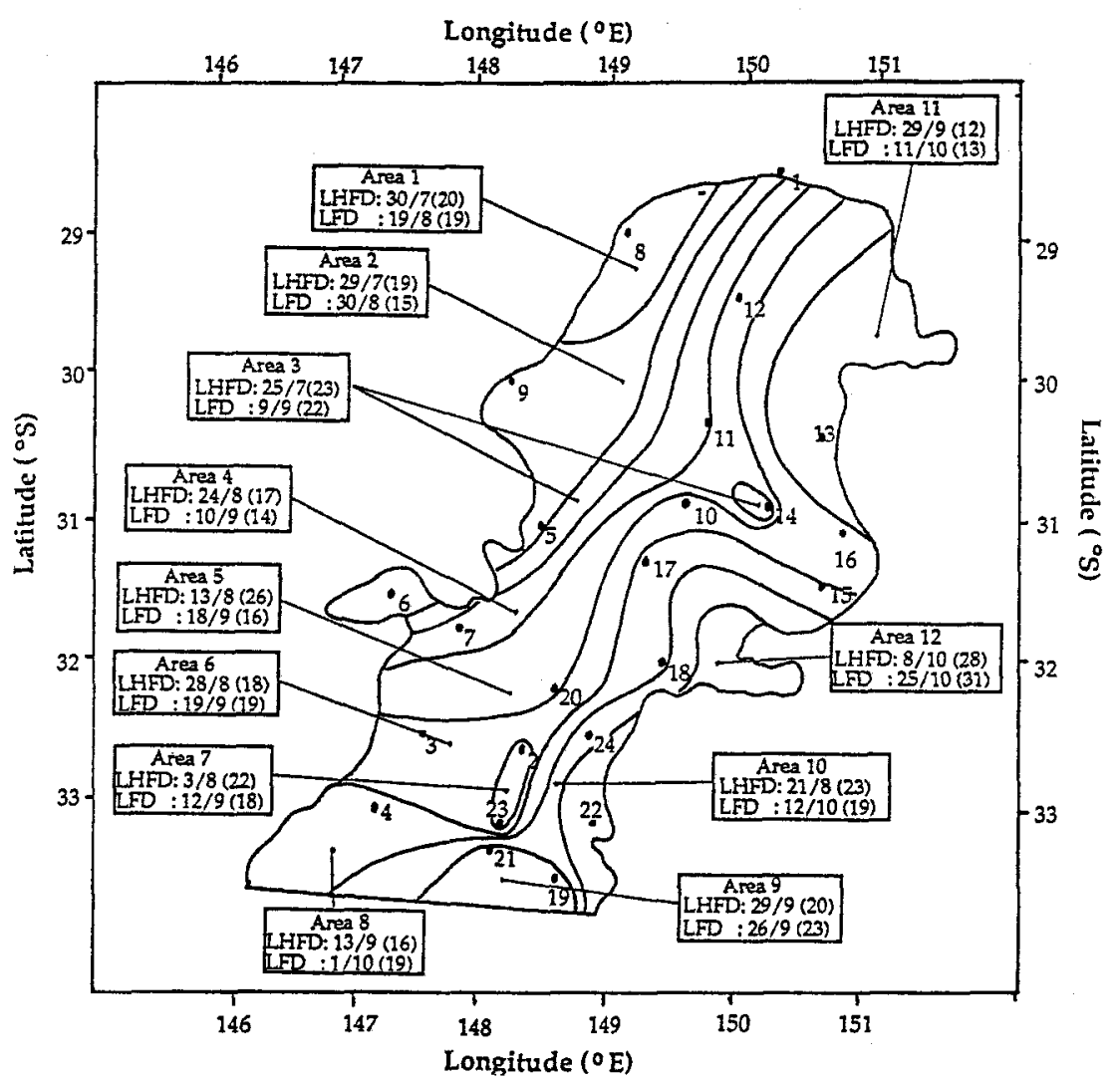

Fig. 4. The division of the region based on the mean dates of last heavy frost (LHFD) and last frost (LFD). The boundary lines shown are based on the cluster analysis and the elevation contours. The tables associated with each area are mean and pooled standard deviation of the dates of last heavy and last frost.

The last date of heavy (or light) frost, $D_{\mathrm{p}}$, for a given level of probability can be derived using the equation:

$$
D_{\mathrm{p}}=m+s * Z_{\mathrm{p}}
$$

where $Z_{\mathrm{p}}$ is the upper $(\mathrm{p} / 2) \%$ point of the standard normal distribution and $m$ and $s$ are the mean and standard deviation of the date of the last heavy (light) frost. As $Z_{5}=1.96, \mathrm{LHFD}_{0.5}$ in Area 1 would be 7 September; in other words, a heavy frost would occur once in 20 years after 6 September. Rearranging the 
equation, the probability of having a heavy (or light) frost after a given date $D$ is given by the value of $\mathrm{p}^{*}$ corresponding to:

$$
Z_{\mathrm{p} *}=(D-m) / s .
$$

\section{August-October frost spell}

The region was divided into three areas according to the four August frost spell characteristics, and into four areas according to those for September and October (Fig. 5). In all areas, the probability of not having a frost during August was very small. In half of the years, there were at least 3,4 and 5 August frost spells of any duration in Areas 1,2 and 3 respectively (Fig. 6a) while the mean of the maximum number of spells was 6,7 and 8 respectively. More than half of these frost spells were more than 2 days in length for Areas 2 and 3 . The mean of the maximum length of an August frost spell was 6, 8 and 14 days for Areas 1, 2 and 3 respectively. For September and October, the number of frost spells and the maximum length of a spell were lower and the differences between areas for the corresponding characteristics were more pronounced (Fig. 6b,c).

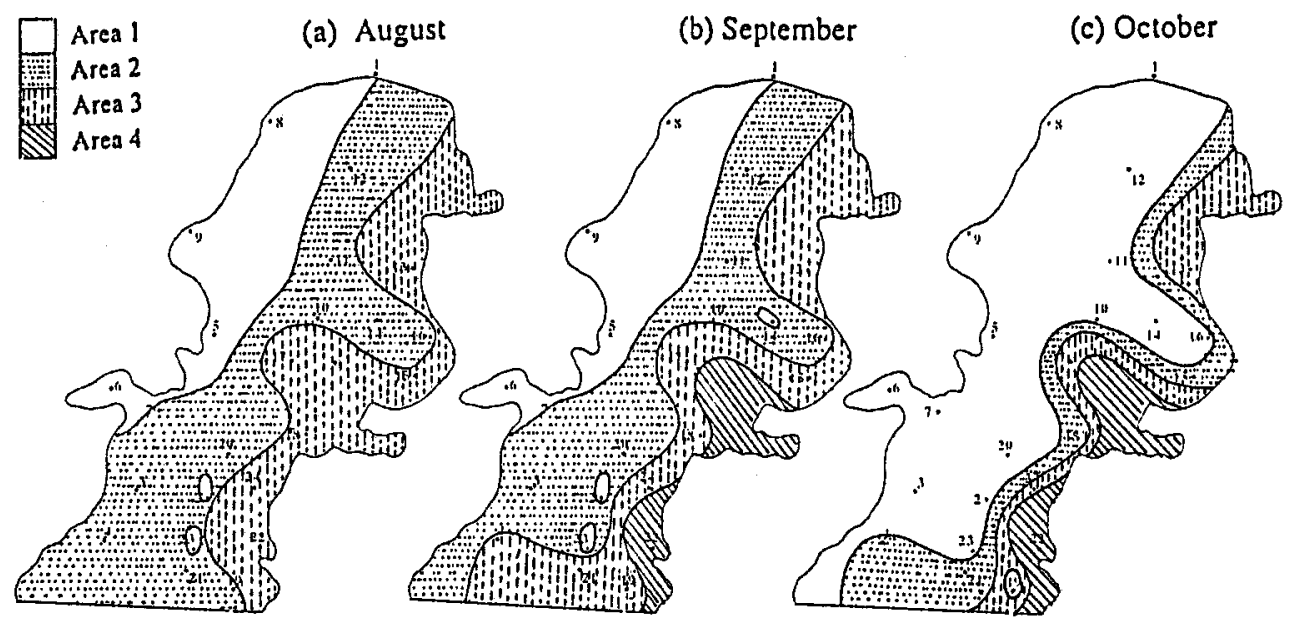

Fig. 5. The division of the region based on the characteristics of frost spells in (a) August, (b) September and (c) October.

\section{Discussion}

The region can be partitioned into two main areas, each containing two homogeneous subareas. Area $I$ is in the western part of the region (lower elevation), and Area 2 in the eastern part (higher elevation; Fig. 2). This indicates that altitude is more dominant than latitude in affecting frost occurrence. This is in contrast to the suggestion of both Gentili (1971) and Gibbs et al. (1978) that both altitude and latitude are the major factors in determining the frequency of frost occurrence. The weak correlation with latitude might be due to the study region covering four degrees of latitude $\left(29.5\right.$ to $33.5^{\circ} \mathrm{S}$.). If the 
region covered were extended, there is a possibility that an effect of latitude might appear, since the frost characteristics at Condobolin, Tullamore and Forbes, which are at low altitude $(<250 \mathrm{~m})$ but high latitude $\left(>32^{\circ} \mathrm{S}\right.$.), are similar to those at sites in Area 2 (Fig. 2; cf. Table 1, Fig. 1).

The relationship between both first and last frost day (FFD and LFD) and altitude was found to be quadratic in Areas 1 and 2. For NFD and PFSI and PNFS4, the relationship was found to be quadratic only in Area 2 (Fig. 3; cf. Fig. 2). Furthermore, in Area 1 the effect of altitude was only significant for NFD (Fig. 3). The variation in NFD was greatest in the northern and western extremities of the region (Table 2). In Area 1, the first frost was much earlier and the last frost much later in the year as the altitude increased from 100 to $200 \mathrm{~m}$. At the higher altitudes, the rate of change in FFD and LFD was almost the same for the two areas. A $100 \mathrm{~m}$ change in altitude would be translated into a 5 day change and a 4 day change in FFD and LFD respectively (Fig. $3 a, b$ ). The effect of altitude on NFD was pronounced in areas above $400 \mathrm{~m}$, but not in areas between 200 and $400 \mathrm{~m}$ (Fig. 3c). Between an altitude of 200 and $300 \mathrm{~m}$ in Area 1, FFD occurred later and LFD occurred earlier than in Area 2 (Fig. 3).

(a) August

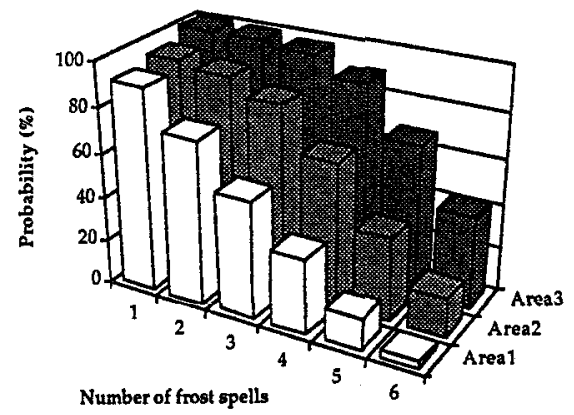

(b) September

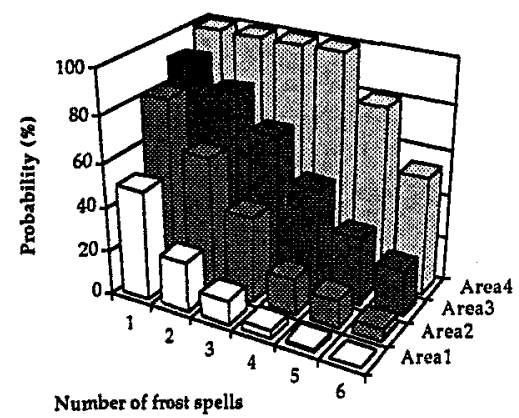

(c) October

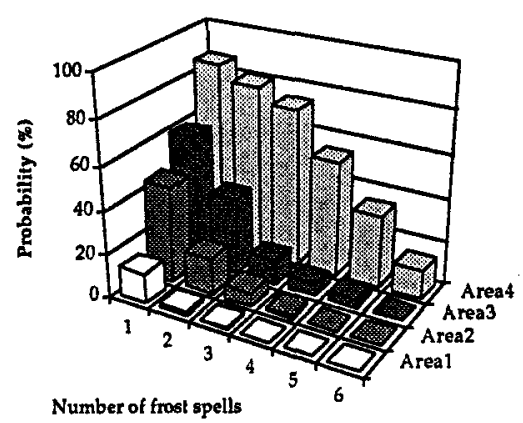

Fig. 6. The probability of having at least the specified number of frost spells in (a) August, (b) September and (c) October.

The existence of a negative linear relationship between the date of first and last frost has been found in other countries, e.g. Eastern Massachusetts, U.S.A. (Baron et al. 1984), and Saskatchewan, Canada (Williams et al. 1988). In our 
study, a weak negative correlation between these two characteristics exists at most sites. Thus, it may be concluded that when the first frost occurs earlier in the autumn, the last frost tends to occur later in the spring.

To maximize yield of wheat, it is necessary for anthesis to occur after the high risk frost period (Single 1987). A low risk frost period can be determined for any site in the region using the means and standard deviations presented in Fig. 4. A late date of anthesis needs to be balanced against the damage that can occur if grain filling takes place during a time of high temperature and/or moisture stress. Field studies with wheat at Trangie (Cooper 1992), Narrabri (McDonald et al. 1983) and Tamworth (Doyle and Marcellos 1974) showed that the highest yield was obtained if the crop flowered in mid September, late September and early October respectively. Each week's delay in anthesis after these dates can reduce yield by $9-16 \%$ (Doyle and Marcellos 1974; McDonald et al. 1983; Cooper 1992). Using Julian days 258, 270 and 277 to represent mid September, late September and early October respectively, the probability of having a heavy frost after these periods is about 12, 3 and $3 \%$ (using Fig. 4). As these field studies are consistent with our study, further validation should be undertaken with other crops when data are available so that the equations (Fig. 3) can be used to estimate frost incidence at any site in the region.

The general frost characteristics at Parkes and Peak Hill which are at a similar latitude to Condobolin, but at a higher altitude, were found to be the same as those at Area 1 (Fig. 2). Gunnedah and Tamworth, which are both at high altitude (Table 1, Fig. 1), were also found to be in Area 1 (Fig. 2). Similar features were also observed in their specific frost characteristics (Fig. 5). Local conditions such as topography (Lawrence 1958; Bootsma 1976; Hammer and Rosenthal 1978; Kalma et al. 1983, 1986; Tabony 1985; Canadas et al. 1988), the type and distribution of vegetation (Wilson 1968), soil type, soil moisture content, air specific humidity and wind speed (Valery and Shakespeare 1975; Avissar and Mather 1988) also affect frost formation. These may account for the classification of these sites.

The approach developed here can be used generally to partition any region into homogeneous areas using cluster analysis allied with expert knowledge. The equations which are then generated will usually fit better than those obtained by simple regression analysis for the whole region, as the latter method is open to bias from local effects.

\section{Acknowledgments}

The authors would like to thank Robin Hicks of the Bureau of Meteorology, Melbourne, for providing us with the frost data used in this study.

\section{References}

Avissar, R., and Mather, Y. (1988). Mapping frost-sensitive areas with a three dimensional local-scale numerical model. Part I: Physical and numerical aspects. Journal of Applied Metetorolology 27, 400-13.

Baron, W. R., Gordon, G. A., Borns Jr, H. W., and Smith, D. C. (1984). Frost-free record reconstruction for Eastern Massachusetts, 1933-1980. Journal of Climate and Applied Meteorology 23, 317-19.

Boer, R., Fletcher, D. J., and Campbell, L. C. (1993). Rainfall patterns in a major wheat-growing region of Australia. Australian Journal of Agricultural Research 44, 609-24. 
Bootsma, A. (1976). Estimating minimum temperature and climatological freeze risk in hilly terrain. Agricultural Meteorology 16, 425-43.

Brown, C. W., and Fitzsimmons, R. W. (1964). Frost: Wheat growers enemy no. 1. Agricultural Gazette NSW 75, 1250-55.

Canadas, C. L., Salcedo, S. T., Bravo, R. E., and Knapp, G. (1988). The vulnerability of indigenous farming systems to climatic variations. In 'The Impact of Climatic Variations on Agriculture. Vol. 2: Assessments in Semi-arid Regions.' (Eds M. L. Parry and T. R. Carter.) pp. 413-28. (Kluwer Academic: Boston.)

Cettour, I. R., and Nissi, J. E. (1985). Wheat breeding in north-east Argentina. In 'Wheat for More Tropical Environments'. A Proceeding of International Symposium, pp. 34-7. (CIMMYT: Mexico.)

Chambers, S. C. (1962). Frost injury of wheat. Journal of Agriculture Western Australia 3, $617-20$.

Chatfield, C., and Collins, A. (1980). 'Introduction to Multivariate Analysis.' pp. 57-81. (Chapman and Hall: New York.)

Cooper, J. L. (1992). The effect of time of sowing and variety on the development and grain yield of irrigated wheat in the Macquarie Valley, New South Wales. Australian Journal of Experimental Agriculture 32, 345-53.

Doyle, A. D., and Marcellos, H. (1974). Time of sowing and wheat yield in northern NSW. Australian Journal of Experimental Agriculture and Animal Husbandry 14, 93-102.

Fischer, R. A. (1979). Growth and water limitations to dryland wheat in Australia: a physiological framework. Journal of Australian Institute of Agricultural Science 45, 83-94.

Fitzsimmons, R. W. (1960). Disease and frost damage in cereals, 1959-1960 season. Agricultural Gazette NSW 71, 434-5.

Fitzsimmons, R. W. (1961). Disease and frost damage in cereals, 1960-61 season. Agricultural Gazette NSW 72, 581-3.

Fitzsimmons, R. W. (1966). Disease and frost damage in cereal crops 1965-6. Agricultural Gazette NSW 77, 550-3.

Fitzsimmons, R. W., and Aitkin, R. L. (1970). Disease and frost damage to cereal crops, 1969-70. Agricultural Gazette NSW 81, 544-50.

Fletcher, D. J., and Boer, R. (1992). 'A Graphical Technique for Assessing the Homogeneity of Regression Coefficients.' (Research Report, Dept of Mathematics and Statistics, University of Otago: Dunedin.)

Fletcher, R. J. (1990). Response to freezing stress in wheat: genetic variability in the field. In 'Proc. 6th Assemby Wheat Breeding Soc. Australia'. pp. 339-45. (Tamworth.)

Fletcher, R. J., and Cullis, B. R. (1988). Evaluation of chromosome substitution lines of wheat (Triticum aestivum L.) for freezing injury suffered during the stem elongation stage of development. Australian Journal of Agricultural Research 39, 111-28.

Gentili, J. (1971). The main climatological elements. In 'World Survey of Climatology'. Vol. 13. (Ed. J. Gentili.) pp. 119-88. (Elsevier Publ. Co.: Amsterdam.)

Gibbs, W. J., Maher, J. V., and Coughlan, M. J. (1978). Patterns of shorter-term change and variability. In 'Climatic Change and Variability. A Southern Perspective'. pp. 135-99. (Cambridge University Press: Cambridge.)

Hammer, G. L., and Rosenthal, K. M. (1978). Frost and minimum temperature probabilities. Queensland Agricultural Journal 104, 177-201.

Kalma, J. D., Byrne, G. F., and Johnson, M. E. (1983). Frost mapping in southern Victoria: an assessment of HCMM thermal imagery. Journal of Climatolology 3, 1-19.

Kalma, J. D., Laughlin, G. P., Green, A. A., and O'Brien, M. T. (1986). Minimum temperature surveys based on near-surface air temperature measurements and airborne thermal scanner data. Joumal of Climatolology 6, 413-30.

Lawrence, E. N. (1958). Temperature and topography on radiation nights. Meteorology Magazine 87, 71-5.

Linacre, E., and Hobbs, J. (1977). 'The Australian Climatic Environment.' (Wiley: Brisbane.)

Loss, S. P. (1988). Factors affecting frost damage to wheat in Western Australia. In 'Frost Injury of Wheat'. Workshop of Wheat Research Council, pp. 24-32. (NSW Department of Agriculture.) 
Marcellos, H., and Doyle, A. D. (1974). Wheat yields-sowing time important on northwest slopes. Agricultural Gazette NSW 85, 14-15.

McCann, J. M., and Rooney, D. R. (1955). The Wimmera championships. Journal of Department of Agriculture Victoria 53, 145-52.

McDonald, G. K., Sutton, B. G., and Ellison, F. W. (1983). The effect of time of sowing on the grain yield of irrigated wheat in the Namoi Valley, New South Wales. Australian Journal of Agricultural Research 34, 229-40.

Paulsen, G. M., and Heyne, E. G. (1983). Grain production of winter wheat after spring freeze injury. Agronomy Journal 75, 705-7.

Rees, D. J., Samiullah, A., Rehman, F., Kidd, C. H. R., Keatinge, J. D. H., and Raza, S. H. (1990). Precipitation and temperature regimes in upland Balochistan: their influence on rain-fed crop production. Agriculture and Forest Meteorology 52, 381-96.

Richards, R. A. (1991). Crop improvement for temperate Australia: Future opportunities. Field Crops Research 26, 141-69.

Singels, A. (1992). Evaluating wheat planting strategies using growth models. Agricultural Systems 38, 175-84.

Single, W. V. (1986). Frost injury and the physiology of the wheat plant. Journal of Australian Institute of Agricultural Science 51, 128-34.

Single, W. V. (1987). Frost injury. In 'Australian Field Crops Vol. 1: Wheat and Other Temperate Cereals'. 2nd Edn, pp. 364-83. (Angus and Robertson: Sydney.)

Syme, J. R. (1973). Quantitative control of flowering time in wheat cultivars by vernalization and photoperiod sensitivities. Australian Journal of Agricultural Research 24, 657-65.

Tabony, R. C. (1985). Relationship between minimum temperature and topography in Great Britain. Journal of Climatology 5, 503-20.

Uemura, K., Mihara, Y., Hanyu, J., and Omato, Y. (1972). Meteorological hazards. In 'Agricultural Meteorology of Japan'. (Ed. Y. Mihara.) pp. 97-125. (Univ. of Tokyo Press: Japan.)

Valery, P., and Shakespeare, W. (1975). The modes of agricultural meteorology hazards. In 'Methods in Agricultural Meteorology'. Developments in Atmospheric Science Vol. 3. (Ed. L. P. Smith.) pp. 167-77. (Elsevier Scientific: Amsterdam.)

Willet, J. B., and Singer, J. B. (1988). Another cautionary note about $\mathrm{R}^{2}$ : Its use in weighted least square regression analysis. The American Statistician 42, $236-8$.

Williams, G. D. V., Fautley, R. A., Jones, K. H., Steward, R. B., and Wheaton, E. E. (1988). Estimating effects of climatic change on agriculture in Saskatchewan, Canada. In 'The Impact of Climatic Variations on Agriculture. Vol. 1: Assessment in Cool Temperate and Cold Regions'. (Eds M. L. Parry, T. T. Carter and N. T. Konijn.) pp. 221-379. (Kluwer Academic: Boston.)

Wilson, G. V. (1968). The use of objective aids and topoclimatic surveys in frost forecasting. In 'Agricultural Meteorology. Proc. on the WMO Seminar Melbourne, Australia Vol. 2'. pp. 541-62. (Australian Bureau of Meteorology: Melbourne.)

Woodruff, D. R. (1988). Frost research in Queensland. In 'Frost Injury of Wheat'. Workshop of the Wheat Research Council. pp. 33-42. (NSW Department of Agriculture.) 
